\title{
De Kant a Fichte
}

\author{
From Kant to Fichte
}

\author{
ALEJANDRO ROJAS JIMÉNEZ \\ Universidad de Málaga (España)
}

recibido: 20.02.2016

aceptado: 22.06 .2016

\section{RESUMEN}

El presente trabajo pretende analizar hermenéuticamente la recepción de Kant por parte de Fichte para mostrar en qué sentido la filosofía de Fichte, con la que se inicia el idealismo alemán, no es ninguna desviación de la línea que va de Hume hasta Kant (como propone por ejemplo el positivismo y su defensa de que la filosofía debía dejar de ser metafísica), sino por el contrario una "continuación” bien fundada de la filosofía kantiana, en la que los límites de la razón son la condición de posibilidad del ejercicio mismo del pensamiento libre que, como acción (Handeln), se concibe como distinto aunque inseparable de la imagen determinada (Nachbild) que el pensamiento mismo produce y del que se debe liberar estableciendo el ideal ( $V$ orbild), proyectándose, reconociéndose -en palabras de Trías- "desgarrado entre su carácter fundacional y originario de actividad pura del pensamiento que se piensa y el resultado derivado de esa acción."

$$
\begin{gathered}
\text { PALABRAS CLAVE } \\
\text { ILUSTRACIÓN, EMPIRISMO, LIBERTAD, IDEALISMO, } \\
\text { DESTINO ÉTICO, IMAGEN }
\end{gathered}
$$

\footnotetext{
ABSTRACT

This paper aims a hermeneutical analysis of the reception of Kant by Fichte to show in what sense the philosophy of Fichte, with which German idealism is started, is any deviation of the line from Hume to Kant (just like positivism for example suggests, and his defense of that philosophy should stop being metaphysics), but rather a well-founded "continuation" of Kant's philosophy, in wich the limits of reason are the condition of possibility of the free thought,
}

Claridades. Revista de filosofía, 8 (2016), pp. 105-125

ISSN: 1889-6855 ISSN-e: 1989-3787 Dl.: PM 1131-2009

Asociación para la promoción de la Filosofía y la Cultura (FICUM) 
that as an action (Handeln) is conceived different but inseparable from the particular image (Nachbild) that thought produces and that should be released setting the ideal (Vorbild), projecting, recognizing -in Trías's words “torn between its founding and original character of pure activity of thought thinking and the result derived from that action."

KEY WORDS

ENLIGHTENMENT, EMPIRICISM, FREEDOM, IDEALISM, ETHICAL DESTINATION, IMAGE

\section{ACLARACIÓN PREVIA: ¿SOBRE EL SIGNIFICADO DE “CONTINUAR”?}

LA DEFENSA DE QUE LA FILOSOFÍA DE FICHTE es una auténtica continuación de la filosofía de Kant merece desde luego una aclaración previa. Habrá quien prefiera hablar de superación, de transformación, y quienes incluso prefieran hablar de ruptura y abandono. Pero frente a la aparente diferencia, en realidad, en todos estos casos se trata sólo de fijarse en unos aspectos preferentemente a otros. Quiero decir, quien habla de superación parece fijarse sobre todo en lo que se abandona, y quien habla de continuación sobre todo en lo que permanece. Quien habla de abandono se fija sobre todo en lo que se desconsidera, y quien habla de rotura sobre todo en lo que se critica o rechaza. Lo que no cabe es pensar que algo sea ciento por ciento una ruptura, una continuación, etc. Un ciento por ciento de ruptura es en realidad un rechazo, del mismo modo que un ciento por ciento de continuación es en realidad una repetición. Frente a estos extremismos parece más sensato reconocer que es preferible hacer uso del plural para hablar de continuaciones, abandonos, rupturas, $\mathrm{y}$ transformaciones que se dan en un mismo autor con respecto a otro autor y su filosofía. Y así, cuando en este trabajo se habla de la continuación de Fichte de la filosofía kantiana, no se rechaza que no haya en efecto abandonos, rupturas y transformaciones, sino que a pesar de ellas hay algo que permanece y en lo que queremos centrar nuestra atención preferiblemente porque es esencial para reconocer una línea, una trayectoria, un proyecto, una tarea que incluso excede las obras de estos grandes autores haciendo entrar en juego otros nombres y otras respuestas.

La idea es, podríamos decirlo así, mostrar en qué sentido la continuación de Fichte de la filosofía kantiana le lleva a unos resultados concretos y propios. Mi tesis, a exponer y analizar en lo que sigue es la siguiente: 
que la filosofía de Fichte continúa, aunque transformándolo, un proyecto que lo hace kantiano, aún cuando su filosofía ya no pueda ser designada más como kantiana si lo que entendemos por filosofía kantiana es un idealismo crítico. Quiero decir, mi tesis es que Fichte transforma la filosofía kantiana para ser fiel a un proyecto que, sin embargo, sí está funcionando en Kant. Hablaré si se quiere de una continuacióntransformación que asume que hay rechazos, abandonos y rupturas, pero que quiere poner el énfasis en lo que permanece y queda; y que, dicho sea de paso, tiene que ver con el reconocimiento del papel principal que juega la libertad en la posibilidad de la filosofía misma.

Hecha esta aclaración previa se entiende que sólo podamos empezar este trabajo realizando una extensa presentación sobre Kant encaminada a exponer eso fundamentalmente kantiano que después veremos que continúa en Fichte, aunque no del mismo modo, sino transformado y reformulado.

\section{KANT Y LA TAREA DE LA FILOSOFÍA}

Entiendo que las siguientes dos tesis podrían ser consideradas como premisas más o menos aceptadas por todos: a) que la tarea fundamental y primera de la filosofía según Kant es la de -bajo la fórmula de una crítica de la razón pura- fundamentar la posibilidad de los juicios sintéticos a priori, es decir, la posibilidad misma de los conocimientos universales y necesarios con la intención de determinar de este modo la posibilidad misma de la filosofía como ciencia. Y b) que la conclusión a la que llega el filósofo de Könisberg es que debemos rechazar la posibilidad de la filosofía "pura" como ciencia por considerar que ésta es el resultado de un uso "ilegítimo" de la razón al actuar desligada de la experiencia.

Kant no concluye desde luego que la filosofía "pura" deba ser rechazada por no ser posible como ciencia, es decir, no hay un rechazo de la filosofía pura, sino que simplemente (aunque no era cualquier cosa) se niega la posibilidad misma de la filosofía como ciencia. Rechazar la filosofía como ciencia no es rechazar la filosofía, sino reubicarla, redescubrir su sitio.

Un rechazo de la filosofía por el hecho de no ser ciencia vendrá después, de la mano de corrientes que emergen en el nuevo orden de la sociedad industrial, es decir, en aquella Europa de la que había salido recientemente Napoleón, y en la que, tras la caída del emperador, se había

Claridades. Revista de filosofía 8 (2016) 
convertido en un problema acuciante la cuestión de cómo conciliar en una sociedad industrializada la idea de progreso revolucionaria con la idea de estabilidad reaccionaria. La solución, según el positivismo, era que el filósofo diera paso al hombre de ciencia de auténtico espíritu positivo; eso sí, bajo la dirección de una sociología que nos dijera la función social de cada ciencia. A mi juicio es una concepción "pesimista" de la libertad la que lleva al positivismo a proponer, frente a la libertad, un método racional que nos garantice cierto éxito ${ }^{1}$ (capacidad predictiva fundamentalmente). Ahora bien, al hacer girar la racionalidad en torno a una idea de verdad pensada en términos de éxito ${ }^{2}$, se traiciona a mi juicio -en lugar de continuar- el núcleo fundamental de la línea kantiana ${ }^{3}$, ya que Kant no tenía fundamentalmente la intención de determinar el mejor método posible para conocer con cierta garantía de éxito, sino la intención de caracterizar la génesis del conocimiento para valorar y entender la peculiaridad del filosófico, haciendo ver que éste tiene su último fundamento en la naturaleza humana. ${ }^{4}$

${ }^{1}$ Para una definición de la concepción del éxito en la ciencia cfr., DIÉGUEZ, A., Filoso-
fía de la ciencia, Biblioteca Nueva, 2005, p. $258 \mathrm{ss}$
2 Aún son muchos incluso hoy en día los que, ensalzando la ciencia y criticando de
cierto tipo de quehacer filosófico, basan su argumentación en el éxito de aquella, des-
considerándose que más allá de lo que entendemos (y que se formula con enunciados
susceptibles de ser verdaderos o falsos) el pensamiento pretende muchas más cosas,
que aunque no ayuden a una empresa exitosa, revelan que para entender bien qué es lo
que significa pensar no hay que obsesionarse con las propiedades de verdad de los
enunciados científicos, sino esforzarse por incluir también los tipos de enunciados que
sirven por ejemplo para orientar nuestra conducta, discutir sobre aspectos sociales de
actualidad, etc. Cuestiones que, tienen todas ellas su origen en la naturaleza humana, y
que son por ello esencialmente humanas. Tanto es así que son cuestiones de las que el
género humano se siente orgulloso de poder establecer (como las ideas en torno a la
libertad) con independencia del éxito y de los límites del conocimiento. Sólo quien
olvida que todo conocimiento es humano, puede creer que hay alguno que puede ser
evaluado al margen de nuestra forma de conocer (que es lo que en el fondo busca un
enfoque positivista o cientista como el de centrarse en el éxito) e incluso dignificarlo
sobre el resto.
3 Y aún así no podríamos dejar de aceptar que también es de algún modo una continua-
ción de la KrV de Kant que se olvida, eso sí, de casi todas las obras kantianas.
4 Resulta muy ilustrativo de este rechazo a la historia del éxito la siguiente cita de Feye-
rabend: "se observa que esa historia oficial, la historia del éxito, no ha sido otra cosa
que el resultado del anhelo, que en realidad la ciencia siempre ha progresado a golpe de
catástrofes y revoluciones y que no hay una sóla teoría científica que no esté libre de Claridades. Revista de filosofía 8 (2016) 
$\mathrm{Al}$ rechazar la filosofía como ciencia y fundamentarla en la naturaleza humana, la línea Hume-Kant permite una reubicación de la filosofía en la que ésta ya no tiene que ver con la universalidad, necesidad y extensividad de sus juicios, sino con la libertad del pensamiento. Lo cual no tiene por qué hacernos pensar que debamos abandonarla. Podríamos optar en su lugar por sacar a la luz, y entender correctamente, el papel que ha jugado la libertad en la historia de las ideas; que es lo que hará -o intentará hacer- el idealismo alemán.

Esta relación del pensamiento con la libertad, lejos de ser una novedad, está presente en realidad desde los inicios mismos de la filosofía ${ }^{5}$ : ésta hace su aparición en la historia de la humanidad justamente ante la necesidad que siente parte de la población griega de defenderse de las manipulaciones que políticos y sofistas aplican a la mayoría de la población, incapaz de defenderse de su poderío oratorio. ${ }^{6}$ Quiero decir: la filosofía nace propiamente con Sócrates y Platón ${ }^{7}$ ante la urgencia de contraponer al discurso persuasivo de los sofistas un nuevo tipo de diálogo desinteresado en el que la meta no podía ser ya tener razón, sino liberar a ésta (a la razón) de cualquier encerramiento en unas creencias (pistis) o imágenes particulares. La verdad, el pensar, tienen un sentido eminentemente liberador. Libertad y verdad no se piensan por separado en la filosofía clásica, sino como dos caras de una misma moneda.

Esto se pierde en el viejo continente con el triunfo del dogmatismo. Y gran parte del mérito de Kant es despertar a sus conciudadanos habiendo sido él a su vez despertado por Hume ${ }^{8}$ - de dicho dogmatismo. Algo que hace introduciendo un sano escepticismo que devuelve la libertad al sitio del que la obsesión por cierta idea de verdad la había destronado. Claro que la filosofía aspira a la verdad, pero en esta aspiración no busca la dominación (una verdad que imponer a los demás), sino la conquista de su propia libertad, al hacernos emprender un camino eminentemente práctico de autonomía y liberación de prejuicios.

serias dificultades" FEYERABEND, P., ¿Por qué no Platón?, Tecnos, Madrid, 2003, p. 53.

${ }^{5}$ Por eso hablaba antes de redescubrir, porque se trata -al menos a mi juicio- de devolver a su sitio.

6 Cfr., ROJAS, A.,"El bien y la intelección en Platón”, Thémata 5/julio-diciembre (2014), 37-68, p. 39ss.

${ }^{7} \mathrm{Y}$ no con los presocráticos, que son más bien pre-filósofos o pre-científicos.

${ }^{8}$ Prolegomena, Akademie Ausgabe, IV, p. 260. 
En virtud de esta libertad, el pensamiento no se detiene ante ningún juicio determinado, no se vuelve dogmático. Es decir, no se detiene en un juicio determinado dentro de los límites estrechos de los juicios sintéticos a priori, sino que es capaz incluso de traspasar los propios límites del entendimiento para seguir pensando, aunque lo que piense ya no pueda ser ciencia. La filosofía por ello, o la razón pura, tiene para Kant un sentido eminentemente práctico: tiene que ver con la libertad, entendida como autonomía, de todo ser racional. Por eso la filosofía de Kant, es lo que hará Fichte, se puede leer con cierto carácter reivindicativo: en tanto que no se trata de dejar de lado la filosofía porque no sea ciencia, sino de entenderla como expresión del pensamiento humano libre.

Hoy puede parecer algo trivial decir que la filosofía es una cosa humana. Posiblemente no tengamos ya ningún reparo en afirmar que incluso "demasiado humana", pero en su momento significó un fuerte contrapunto al dogmatismo dominante en Europa. En el fondo, lo que se estaba poniendo sobre la mesa es que el hombre, más allá de un conocimiento universal y necesario es capaz de realizar juicios racionales cuyo único fundamento es su libertad para trascender los estrechos límites del entendimiento. La cuestión, o la alternativa, es pues que esta misma ligazón a la libertad puede ser visto como algo negativo y que evitar (positivismo) o como un hecho en sí que debemos analizar y entender en su peculiaridad; que es lo que en realidad pretende hacer Kant; y lo que continuará haciendo el idealismo alemán, si bien, con una modificación importante: desde la consideración de que todo pensamiento (y no solo la racionalidad práctica), como actividad, es un ejercicio de libertad; es decir, también el científico.

El idealismo alemán es por ello una demoledora afirmación de la libertad del pensamiento frente al positivismo. Según Heidegger, sólo Nietzsche -según él el último metafísico - eleva esta afirmación de libertad más allá del idealismo alemán en la medida en que afirma la relación pensamiento-libertad sin intentar armonizarlo con la verdad. Ciertamente para el idealismo alemán es tarea primordial, y ello frente a Nietzsche, entender el lugar de la verdad después de afirmar una relación semejante entre libertad y pensar. Hegel, por ejemplo, el idealista absoluto, la sitúa a

9 "La metafísica de Nietzsche, como consumación de la metafísica moderna, es al mismo tiempo consumación de la metafísica occidental y con ello -en un sentido bien entendido- el fin de la metafísica en general”, HEIDEGGER, M., Nietzsche. Der europäische Nibilismus, GA 48, p. 253.

Claridades. Revista de filosofía 8 (2016) 
ésta como meta del proceso de liberación del pensamiento -llegando a desvalorar que la auténtica meta es sin embargo la libertad misma- que es lo que Nietzsche sí se atreve a decir después; y posiblemente también -y antes que él- el último Schelling. ${ }^{10}$

Pero quisiera centrar el análisis en el inicio mismo del idealismo alemán, en Fichte. Pues toda esta introducción tiene principalmente la intención de hacer comprensible la siguiente idea: que cuando Fichte lee a Kant de ningún modo va a encontrarse con una obra que rechaza la filosofía al rechazarla como ciencia, sino justamente con una obra que defiende que la filosofía tiene directamente que ver con la libertad. Cuando Fichte, siendo aún un estudiante, lee la $\mathrm{KrV}$ experimenta una confesada revolución ${ }^{11}$ que le hace vivir "in einer neuen $W$ elt" ${ }^{12}$ al permitir que aquel "sentimiento de libertad propia" pudiera dar paso a un auténtico reconocimiento de nuestra libertad (que aquí significa lógicamente Autonomie der Vernunft) más allá del mero sentimiento. La libertad es pues, el auténtico tema que Fichte lee en Kant y sobre el que se va a apoyar todo el enorme edificio de esa era crítica que recibe el nombre de Idealismo Alemán. Y por ello neustra tesis será que la filosofía de la libertad de Fichte es una continuación de Kant; sin que esto nos impida hablar al mismo tiempo de rupturas, abandonos, transformaciones...

Desde luego sin la $\mathrm{KrV}$ no se habrían podido fijar los límites que nos permiten hablar de la trascendencia, del uso puro de la razón. Al fijar los límites del entendimiento, lo que Kant nos ha permitido es entender en qué sentido la filosofía es un ejercicio de libertad y trascendencia. El punto de partida es que en la práctica, las decisiones racionales no son ni necesarias ni universales, sino libres (autónomas), y no podrían ser libres si fueran necesarias y universales. La filosofía es también sólo posible como ejercicio libre del pensamiento, transgrediendo aquellos límites del entendimiento que produce un conocimiento necesario y universal. La filosofía sólo es posible porque somos libres, porque nuestra libertad nos permite abandonar aquellos estrechos límites del entendimiento. Es desde luego racional, aún cuando nuestras respuestas no aspiren a ser universales ni necesarias; porque a lo que aspiran es a ser autónomas.

\footnotetext{
${ }^{10}$ Cfr., ROJAS, A., Das Potenzlose, Olms, Hildesheim, 2014.

11 GA III I, 193.

12 GA III I, 167.
} 
Ahora bien, según Kant al limitarse a hacer ciencia el pensamiento tiene que contenerse y ser crítico, y es sólo en la práctica cuando debe ser puro, porque no se debe contener su ejercicio libre (sin subordinaciones, ni siquiera a la experiencia). Pero Fichte será desde luego más contundente, más romántico: para Fichte resultaba claro que la razón teórica está igualmente ligada a la libertad, porque la libertad del pensamiento debe extenderse a todo pensamiento; no sólo al práctico, o quizás mejor dicho: la libertad del pensamiento debe extenderse a todo pensamiento porque todo pensamiento es práctico ${ }^{13}$ y deriva, también la teoría, de una absoluta exigencia de acción. ${ }^{14}$ Lo podríamos decir así: en todo pensar prima -según Fichte- el deber (sollen) sobre el conocimiento del ser. Es decir, no prima el conocimiento determinado, el Bilderwelt, sino el "tú sencillamente debes" (Du sollst schlechthin"). Este "debes" es eminentemente práctico, porque en este "debes" (tengamos en mente una expresión del tipo "creo ${ }^{16}$ que lo que debo hacer es..."17) designamos un tipo de autoconciencia inmediata por la que tomamos conciencia de que no sólo sabemos cosas, sino que este saber nos impulsa a la acción, a querer hacer, a pensar no ya un Nachbild, sino un Vorbild al que debemos dar forma.

Esto no ocurre por supuesto después de pensar. Más bien habría que decir lo contrario: es la causa final del conocimiento "el principio (Princip) de los principios (Grundsätre)". ${ }^{18}$ Se produce aquí un juego que es a mi juicio la marca de identidad del idealismo alemán: sea o no sea ciencia lo que se piense, pensar es siempre poner en juego la dualidad insuperable entre límite/finitud (lo pensado) y la actividad infinita que es el pensar. En la inseparabilidad de esa dualidad está la clave de la idea de libertad romántica que sucede a la Ilustración, pero que no es una ruptura, sino una continuación, de la propuesta kantiana.

13 "Das Ich geht nicht darin auf, theoretisches Wissen zu sein, sondern es ist auch praktisches Bewusstsein und entsprechendes Handeln. Gegenüber dem blossen Wissen wird dieses praktische Bewusstsein als real verstanden" JACOBS, W. G., Johann Gottlieb Fichte. Eine Einführung, Suhrkamp, Berlin, 2014, p. 99.

14 SW I 327.

15 SW I 327.

${ }^{16}$ Glaube es efectivamente la expresión que utiliza Fichte: GA I 6, 257; SW II 253.

${ }^{17} \mathrm{El}$ ejemplo que pone W. G. Jacobs es "Wir wissen nicht nur etwas, zum Beispiel das Buch in der Hand, wir wissen auch, dass wir etwas sollen, dass uns etwas antreibt zu handeln" Einfübrung o. c. p. 99.

18 Duque, Historia de la filosofía moderna. La era crítica, Akal, Madrid, 1998, p. 215. 
En compendio, y como resumen de esta introducción: según el positivismo hay una línea de Hume a Kant que se rompe con el idealismo alemán. Y es la consideración de que la filosofía debía dejar de ser metafísica, para convertirse en una suerte de ciencia social. Una afirmación semejante la podríamos poner perfectamente en boca de Comte. Pero hay algo que el secretario del conde Saint-Simon no tiene en cuenta: que lo que importa de esa línea Hume-Kant es el hallazgo de que la filosofía es una práctica humana, una acción de los hombres. Lo que cae, no es la filosofía pura, sino el dogmatismo filosófico, es decir, la consideración de que las supuestas verdades filosóficas sean independientes del sujeto que las piensa. La consecuencia no debería ser en mi opinión proponer una sociología que regule "dogmáticamente" la ordenación de todas las ciencias según un sistema en el que aquellas resuelven cualquier problema de la vida humana. La consecuencia debe pasar por el contrario por introducir cierto escepticismo en la filosofía: haciéndonos tomar conciencia de la importancia del límite y de la finitud de nuestros conocimientos. Y en la línea de esta segunda alternativa, quiero decir: después de comprender que la afirmación del límite es la única manera de entender la libertad del pensamiento, extender esta idea a todo tipo de pensamiento; comprender todo pensamiento, también el científico, como una consecuencia de la libertad y de la finitud. Fichte es un auténtico continuador de esta línea, sin que esto signifique que en dicha continuación no haya efectivamente abandonos, transformaciones, rupturas que sacar a la luz.

\section{ACLARACIÓN DE LA INFLUENCIA DE HUME EN LA CONCEPCIÓN KANTIANA DE LA FILOSOFÍA.}

La propuesta de que el idealismo alemán es una auténtica continuación del proyecto kantiano frente a la crítica positivista podría enfrentarse a la siguiente objeción: que el autor que salva a Kant de su dogmatismo es Hume, el emprimo inglés, sobre el que se levanta el positivismo y al que se enfrenta el idealismo. Al respecto defenderé la tesis siguiente: que en realidad no es el emprimo el que salva a Kant del dogmatismo, sino la ilustración ${ }^{19}$, pues si bien el empirismo había aseverado que todo

\footnotetext{
${ }^{19} \mathrm{Y}$ no sólo la inglesa, recordemos que es el retrato de Rousseau el único que adornaba las paredes de su cuarto de estudio, de quien admiraba su ideal de sociedad civil propuesta en El contrato Social. El impacto que le supuso la lectura del Emilio (que hizo que interrumpiera sus paseos habituales).
}

Claridades. Revista de filosofía 8 (2016) 
conocimiento tiene su origen en la experiencia y que en ésta debíamos reconocer las limitaciones del conocimiento, Hume entendió más allá del empirismo que no podíamos quedarnos en una mera exposición acerca de los límites y principios del entendimiento humano, sino que era necesario concluir la investigación con una "ciencia de la naturaleza humana". Si se tiene en cuenta esto, o lo que es lo mismo, que Hume pertenece a la ilustración inglesa y que por ello no es un mero crítico empirista de las antiguas ideas metafísicas que la revolución científica hizo entrar en crisis, entonces se entiende mucho mejor el proyecto kantiano, puesto que se observa con claridad que la clave de la influencia reside en haberle mostrado que la metafísica -y la filosofía en general- es una praxis humana. Como dice Heidegger, la filosofía de Kant es, antes que una teoría del conocimiento, una fundamentación de la metafísica en la naturaleza humana. ${ }^{20}$

No quiero decir que Hume no fuera efectivamente un crítico de aquellas ideas metafísicas, seguramente es uno de sus grandes críticos. Lo que intento es más bien resaltar que Hume es más que eso: lo que hace Hume es investigar los fundamentos de esas ideas en la naturaleza humana. $Y$ esto no es lo propio del empirismo, sino de la ilustración y su consigna de pasar de un orden basado en Dios a un orden basado en el hombre. La idea revolucionara de aquel Tratado de la naturaleza humana era la de sostener que ésta era el fundamento de todas las ciencias, alcanzándose una conciencia muy sólida de la dependencia de todo saber y orden social respecto del hombre.

Es por ello que a la hora de entender en qué sentido el inglés salva al alemán de su dogmatismo, podríamos decir que no es tanto el empirismo inglés, sino que más bien es la ilustración inglesa (eso sí, impensable sin el empirismo inglés) la que, por mediación del escepticismo ilustrado de Hume, despierta a Kant de su sueño dogmático. Kant deja de ser un dogmático para convertirse en un ilustrado de la mano de Hume, y es por ello que también Kant, como buen ilustrado, tiene la intención de no limitarse a una crítica de las viejas ideas metafísicas, sino que busca sobretodo encontrar una respuesta en la naturaleza humana.

20 "La presente investigación se propone la tarea de interpretar la Crítica de la razón pura de Kant como fundamentación de la metafísica", HEIDEGGER, M., Kant y el problema de la metafísica, trad. C. Ibicher, FCE, México, p. 9.

Claridades. Revista de filosofía 8 (2016) 
Elevando el empirismo a su máxima expresión, ${ }^{21}$ con Hume el empirismo comienza a ser algo nuevo; algo que quizás podríamos definir como naturalismo moderno. ${ }^{22}$ Pero no quiero entrar en una guerra terminológica, pues lo único que pretendo decir es que Hume es sobre todo un ilustrado: un ilustrado inglés desde luego, y por ello un ilustrado muy marcado por el empirismo; si se quiere un empirista ilustrado que a diferencia de sus antecesores tiene una conciencia ilustrada muy clara de la exclusiva dependencia de todo orden social y del saber al hombre.

$\mathrm{Al}$ situar el origen de las ideas metafísicas en la naturaleza humana, Hume supone una auténtica sacudida para un dogmático. Al dogmático el empirismo no le supone en realidad ningún problema serio. Cabe apreciar según Duque incluso que hay dogmáticos empiristas, como lo fue Berkeley, del mismo modo que hay racionalistas escépticos, como lo fue Spinoza. ${ }^{23}$ Lo que se opone al dogmatismo no es pues el empirismo, sino el escepticismo (en concreto el escepticismo ilustrado). Por eso Kant suele dividir la historia de la filosofía en dogmáticos y escépticos, y no entre racionalistas y empiristas. Y por eso para Kant esta tarea no deja de lado el racionalismo, sino que recoge lo "mejor" de las dos corrientes para derrotar al dogmatismo.

\section{TRASPASAR LOS LÍMITES DEL ENTENDIMIENTO COMO TAREA DE UNA RACIONALIDAD LIBRE: RUMBO TEMPESTUOSO E IMPETUOSO HACIA EL YO COMO FUNDAMENTO.}

En Alemania la Ilustración llega tarde. Tanto es así, que se suele hablar incluso de un nuevo período: el prerromanticismo. Pertenecen a esta época crítica Kant, Herder, Goethe, Jacobi, Lavater, y toda una estirpe de pensadores que hacían que Alemiana no tuviera que mirar más fuera, sino a sí misma, para buscar su propio camino y su identidad intelectual. Justamente cuando franceses e ingleses han dado lo mejor de sí es cuando despierta el genio alemán. Con la ventaja de que ya no había que des-

${ }^{21}$ Cfr., GARCÍA, J., "El empirismo y la filosofía hoy”, en ROJAS-GARCÍA (eds), El idealismo alemán y sus consecuencias actuales, Contrastes, Suplemento 19, 2014, p. 162.

22 STROUD, B., Hume, Routledge \& Kegan Paul, Ltd., London, 1977, 1-280. Que corrige a mi juicio la excesiva positivización de Hume por parte de Russell y los atomistas lógicos, que lo entienden principalmente como un positivista que sostiene que todo el conocimiento proviene de la experiencia, desmereciendo el proyecto de Hume de realizar una fundamentación en la naturaleza humana.

${ }^{23}$ Cfr., La era crítica op. cit., p.45 (nota al pie 24).

Claridades. Revista de filosofía 8 (2016) 
gastarse luchando contra las viejas ideas (esa batalla la tuvieron otros), sino que la tarea era más bien la de crear tierra firme entre tanta destrucción: había que analizar críticamente el conocimiento para esclarecer qué se puede saber y qué cabe esperar.

Alemania empezaba sin embargo a agitarse por un nuevo movimiento intelectual: el Sturm und Drang según acertó a calificar Schlegel. Seguramente el menos influyente de todos los pensadores alemanes en este movimiento revolucionario fue Kant, que fue considerado un aparente continuador del dogmatismo de Wolff. Mucho más atractivo para los alemanes resultaba Herder: sus viajes por Europa, su rebeldía contra las aburridas lecciones de los profesores, su oposición a la ilustración de los berlineses... Si el hecho de que la ilustración alemana llegara con retraso tenía como positivo la madurez con la que se expresó la Ilustración en Alemania, tendrá por contrapartida el hecho de que Europa estaba empezando a ser sacudida por una nueva generación a los ojos de la cual Kant parecía ser cosa del pasado.

Si había algo de lo que estuviera cansada esta nueva generación es de los límites a la libertad y al pensamiento. La noción de límite, ya sea entendida como medida o equilibrio (o de cualquier otro modo) es la noción central del mundo clásico. Y si contra algo choca aquella tempestad del Sturm es justamente contra esa idea de límite, frente a la cual vendrá a luchar el naciente espíritu romántico. ${ }^{24} \mathrm{Si}$ como he intentado expresar más arriba la filosofía de Kant es sobre todo una filosofía del límite, entonces es normal que no encontrase eco entre unas generaciones que ya no querían hablar más de límites: sienten un impulso irrefrenable a crear algo nuevo, que si bien aún no llega a ser el crear por crear de Nietzsche, no es desde luego un impulso creador menos vigoroso, y sí el antecedente claro de la línea Nietzsche-Heidegger. ${ }^{25}$

Pero para ser justos hay que decir que se puede observar ya en Kant un intento incesante por abandonar los límites del entendimiento que él había establecido. Aunque en 1781 considera que todo conocimiento sintético de la razón pura en su uso especulativo es imposible ${ }^{26}$, en 1788

${ }^{24}$ Cuando Schleiermacher y Schelling vuelven a Platón, es justamente para repensar la idea de límite: uno para revitalizar los diálogos, otro para recuperar en Platón el género de lo ilimitado olvidado por la tradición.

${ }_{25}$ Cfr., ROJAS, A., La denda inconfesada de Heidegger, Universidad de Málaga, Málaga, 2014.

${ }^{26} \mathrm{KrV}, \mathrm{B} 824$.

Claridades. Revista de filosofía 8 (2016) 
habla ya de un principio práctico que tiene su fundamento en la libertad (autonomía de la razón práctica) y en 1790 aparece la conquista de la heautonomía de la facultad de juzgar, señalando un principio propio para su uso lógico y estético. ${ }^{27}$ Pero Kant tendría que esperar a Fichte para ser nuevamente escuchado con pasión. Los jóvenes alemanes ya tenían en la cabeza otra cosa: querían poner de relieve los aspectos individuales frente a los universales, querían defender el sentimiento de individualidad frente al de pertenencia al género humano, querían poner de relieve su forma de sentir, su pasión... ya no eran ilustrados. Y Kant parecía haber llegado tarde, para dar voz a una época que entraba en su ocaso.

O al menos así parecía ser hasta encontrar a un joven Fichte capaz de verter en ella todo el entusiasmo de su pasión. Es entonces cuando se revalora la filosofía del viejo ilustrado que parecía condenada al olvido. Pero puesto que el joven Fichte no era un ilustrado, y aunque la exquisita exposición de Kant con la que acababa de obtener forma toda una épo$\mathrm{ca}$, encontraba por fin un joven atento e inteligente que la entendiera, sin embargo, ni siquiera él podía entender ya -el peso de la historia juega aquí un papel decisivo- por separado la receptividad y la espontaneidad. Quiero decir: si Fichte tenía claro algo es que la libertad no puede venir después, sino que tiene que estar ahí desde el principio ${ }^{28}$. Fichte no sólo lo continúa transformándolo (según se ha aclarado el modo como debemos entender "continuar"), sino que lo salva y lo recupera.

El caso es que Fichte cree que se puede leer a Kant, aunque al kantismo esto le resulte anti-kantiano y profanación (porque esta continuación no es una repetición), poniendo la libertad al principio: el Ich que no es sustancia, sino la actividad (Tätigkeit) "infinita" que "soy yo",29, que pienso como sustancia sólo al objetivarla. Por ello cuando Fichte lee a Kant el yo pienso kantiano se convierte en un yo puro en el sentido de una intuición que se autopone. Este yo garantiza la unidad entre lo sensible y lo inteligible y es capaz de resistir todo escepticismo. Sin éste, sin escepticismo, tampoco hay ya ilustración. No se trata de volver desde luego al dogmatismo, sino que se inicia algo nuevo: el idealismo. A Kant su criticismo le impedía hablar de un yo puro y absoluto como actividad

27 "el hecho de que la facultad de juzgar posea un principio a priori es el gran novum sobre el que erige la KU" CUBO, O., Kant. Sentido común y subjetividad, Plaza y Valdés, Madrid, 2012.

${ }^{28}$ Cfr., La era crítica o.c., p 213.

${ }^{29}$ GA I 2, 258. 
originaria, sin nada de pasividad. Para Fichte, por el contrario, nada hay más evidente que un yo infinito ligado a la eclosión romántica. ${ }^{30}$ Con Fichte se inaugura una época si no ilustrada sí ilustre para la filosofía, que parece tomar la forma de un "spinocismo invertido" o un "materialismo sin materia" 31 ya que al lado de la razón pura todo lo demás es nada: el idealismo alemán.

\section{FiCHTE SACA A KANT DEL OLVIDO, PARA CONSTRUIR SOBRE ÉL UNA FILOSOFÍA POSTKANTIANA DONDE LA LIBERTAD ESTÁ AL PRINCIPIO.}

Cuando defiendo que Fichte continúa a Kant, no digo que hace algo nuevo, sino que lo que hace no es anti-kantiano; más bien postkantiano. Es un Kant no leído a los ojos de un ilustrado, es decir, cuando la Ilustración ha quedado atrás.

Después de Kant, y su fundamentación de la filosofía y el saber en la naturaleza humana, el dogmatismo sufre un duro revés. Pero esto le supuso a Kant una oleada de críticas: fue muy criticado por continuar el escepticismo humneano, ${ }^{32}$ y son tantos los fuertes abiertos contra el criticismo que posiblemente no hubiera sobrevivido si no llega a entrar en escena Fichte; decidido a elaborar una doctrina de la ciencia que, sin apoyo en la experiencia, esclareciese cómo conocemos al tiempo que justificase la necesidad de la filosofía (entendida aquí como saber del saber $^{33}$ ). Fichte pues, rescata a Kant, si bien para transformarlo, no para repetirlo. Pero en ningún caso rechazarlo (como hace el positivismo con aquellas obras kantianas que no son la $\mathrm{KrV}$ ), sino para continuar el diálogo, la reflexión, la tarea.

Fichte se presenta ante Kant en 1792, con 30 años, y se encuentra con un ilustrado hambriento y sin fortuna de ya 68 años, que creía que el joven al que lo separaban dos generaciones continuaría su proyecto crítico. Fichte empezaría su docencia en 1794 en Jena con sus famosas lecciones sobre el destino del sabio, que es su exposición más completa de la ilsutración. Y al mismo tiempo comenzaba sus clases sin demasiado éxito. Si Kant no había sido muy escuchado, no le esperaba -al menos al principio- un futuro mucho más esperanzador a Fichte. Muy pocos se-

\footnotetext{
${ }^{30}$ Leyte, "infinito romántico", en Las consecuencias actuales del idaelismo alemán o.c., p 221.

${ }^{31}$ GA III/3, 227.

${ }^{32}$ Cfr., La era ciítica o.c., p. 160 ss.

${ }^{33}$ Erste Einl.; SW. I, 474.
} 
guidores. Pero no cualesquiera: Hölderlin, Schelling y Hegel se encontraban entre quienes seguían sus enseñanzas. No siempre -casi nunca- plegándose a Kant, discutiendo y criticándolo desde luego muchas veces, no reconociéndose en el kantismo por supuesto, pero construyendo una filosofía postkantiana, teniendo siempre a Kant ante la mirada; una filosofía que recibirá el nombre de idealismo trascendental o alemán.

Fichte no sólo no tuvo demasiado éxito al principio, sino que sus enseñanzas fueron consideradas muy peligrosas. Llegó a perder su cátedra y tuvo que marchar a Berlin. Cuando en 1806 Napoleón derrota a los prusianos en la famosa batalla de Jena tomando Berlín, Fichte, que había defendido antes la revolución francesa (influenciado por las ideas ilustradas de Kant) reorienta su tarea en provocar un levantamiento popular contra Napoléon. Es la época de los famosos discursos a la nación alemana; el origen del nacionalismo alemán. Si bien, seamos justos, no tuvo mucho éxito tampoco en esta empresa. Ahora bien, Fichte fue puesto al frente, como rector, de la nueva Universidad de Berlin, llamado a estar al frente de la nueva universidad en la que el reino de Prusia quería fundamentar su nuevo poder con la marcha de los franceses en 1812 tras la derrota de Moscú. Y esto, desde luego, cambia el decurso de los acontecimientos.

De algún modo, la gran novedad de la lectura de Fichte se deja ver en la transformación de la vieja pregunta kantiana de ¿cómo es posible la metafísica como ciencia? que cede su lugar central a la pregunta ¿cómo es posible una ciencia del saber? Este paso resume con bastante precisión la tarea de la filosofía para Fichte. Dicho brevemente y como preludio del siguiente apartado diré de momento que la tarea de esta filosofía ya no era la de analizar la filosofía o la metafísica, sino el saber mismo que prometía un ajustar cuentas con el papel de la libertad en la posibilidad misma del pensar. Un saber del saber que por supuesto pareciera ser imposible a primera vista ya que el saber es siempre saber de algo y no de sí mismo. Debe partir, digamos, de un factum o "ein Gehalt als wahr" que no podemos demostrar ni determinar porque es justamente el punto de partida ${ }^{34}$ y éste no puede tener ningún fundamento ${ }^{35}$ Este punto de partida será para Fichte la autoconciencia (Selbstbewusstsein). Ésta no sería un objeto que pudiéramos separar de la representación, del objeto de con-

${ }^{34}$ GA I 2, 255

35 GA I 2, 256.

Claridades. Revista de filosofía 8 (2016) 
ciencia, ya que sólo puede iniciarse su búsqueda si nos percatamos de que el objeto de conciencia es al mismo tiempo el lugar del reconocimiento reflexivo de la conciencia respecto de sí misma, reconociéndose razón y espíritu. Pues bien: en esta conciencia, y no fuera, descubrimos algo real (más real que toda representación), un impulso que nos empuja, que nos mueve, nos libera de toda determinación.

\section{LA FILOSOFÍA DE FICHTE: \\ LA IMAGEN Y EL DESTINO ÉTICO DEL HOMBRE.}

En 1800 aparece en Berlín Die Bestimmung des Menschen. Una respuesta a Jacobi, que criticaba la posibilidad de que existiera un saber de lo inmediato. Esta obra, que podría ser considerada como una presentación de la WL, también era una defensa respecto de la acusación de ateísmo. Pero si me interesa a mí para este trabajo es por la siguiente idea: dice Fichte que el hombre está en la naturaleza y es una parte de ella. Habla de Bestimmungen der Natur; presenta la naturaleza como una fuerza con poder causal sobre los hombres. Nuestra misma conciencia de libertad se explicaría como parte de esta fuerza natural. Aquí Fichte, como había hecho Spinoza, es rotundo: estamos determinados, somos expresión de la fuerza de la naturaleza. ${ }^{36}$ Pero ésta no es la conclusión de Fichte. Retoma el kantiano Habe Muth dich deines eigenen Verstandes zu bedienen ${ }^{37}$, y nos llama la atención sobre el hecho de que vivimos en una suerte de Bilderwelt, que el mundo que conocemos (el reino del saber) es una representación, un mundo de imágenes.

Si aceptamos esta vertiginosa afirmación descubrimos, en la conciencia y no fuera de ella, algo real (más real que toda representación): un impulso, einen Antrieb, que podríamos designar como querer (wollen), y que designa einen Vorbild, un ideal, einen Zweckbegriff que nos mueve y nos empuja más allá del saber: al deber (sollen). El Yo, la ichkeit, no se detiene en el saber, sino que lo sobrepasa, lo desborda, porque es inagotable, infinito, activo...y toda determinación sólo es ocasión para que dicha infinitud se abra paso. Más allá de toda esta realidad, tendríamos que hablar de la realdad de las cosas, las cuales quedan registradas como una

\footnotetext{
36 "Ich bin eine dursch das Universum bestimmte Aeusserung einer durch sich selbst bestimmten Naturkraft" GA I, 6, 207; SW II 189.

${ }^{37}$ KANT, I., Schriften, VIII 35.
} 
serte de no-yo (Nicht-ich), una cosa imaginada ${ }^{38}$ como efectiva que nunca estará presente (que no es intuible): irrepresentable y esquiva. El verdadero objeto del pensar es pues lo pensable y la pensabilidad. ${ }^{39} \mathrm{Y}$ al centrarnos en este objeto del pensar descubrimos que no sólo sabemos cosas, sino que debemos hacer algo con esas cosas que sabemos. En este sentido distingue entre Nachbild (reproducción de la realidad) y Vorbild (el ideal, ejemplo, modelo...) al que debemos darle forma, y que no es un saber teorético, sino práctico ${ }^{40}$.

Para el idealista alemán, el saber no es sólo saber de cosas (si por cosas entendemos Nachbilden) que están en la conciencia, sino que desborda ese límite, el de la presencia, para lograr a través de la acción ein freies und vernüftiges Leben. ${ }^{41}$ No es ya que el saber nos hace libres, nos libera de los prejuicios y de la heteronomía, sino más bien, que porque somos libres hay saber ${ }^{42}$ y hay mundo conocido, porque "el saber es el ser de la libertad"43; y siendo así, no se conoce para representarse el mundo, sino que el conocer es el modo en el que la libertad se realiza. Lo que pone en juego una inagotable dualidad finitud-infintud que hace bien merecida la denominación del idealismo de Fichte, frente a las sugerencias de Hegel, como idealismo de la libertad.

Más tarde, Heidegger dirá: "Ursprünglich existenzial gefaßt, besagt Verstehen: entwerfend-sein zu einem Seinkönnen, worumwillen je das Dasein existiert $^{\text {,4 }}$. Fichte anticipa, o quizás mejor dicho, Heidegger continuará la interpretación fichteana, aunque fundamentándola más en Aristóteles que en Fichte, haciendo valer el carácter práctico, o quizás mejor vital y

\footnotetext{
38 SW I 234.

${ }^{39}$ SW I 242.

40 "Das Ich geht nicht darin auf, theoretisches Wissen zu sein, sondern es ist auch praktisches Bewusstsein und entsprechendes Handeln" JACOBS, W.G., Johann Gottlieb Fichte. Ein Einführung, Suhrkamp, Berlin, 2014.

${ }^{41}$ „Der Zweck des Erdenlebens der Menschheit ist der, dass sie in demselben alle ihre Verhältnisse mit Freiheit nach der Vernunft einrichte" GA I 8, 198; SW VII 7.

42 "Y como la conciencia, como actividad representativa, no es posible sin inteligencia, o mejor, es una con la inteligencia, hay que poner en el fundamento de la misma el carácter práctico del Yo: ninguna inteligencia, por tanto, sin libertad" RAMOS, M., "La libertad en el principio de la Doctrina de la Ciencia de Fichte", Quaderns de filosofia $i$ ciència, 36, 2006, pp. 51-59, p. 58.

43 "Ich sage, das Wissen schlechtweg in seiner inneren Form und Wesen ist das Seyn der Freibeit" Die Thatsachen des Bewusstseins (1810), II550.

44 HEIDEGGER, M., Sein und Zeit, GA 2, p. 336.
}

Claridades. Revista de filosofía 8 (2016) 
existencial, del saber y el comprender. Si el comprender está interpretado como un proyectarse, está claro que su importancia no va a recaer en llevarnos a una supuesta verdad dogmática, sino en su abrirnos caminos y posibilidades, liberándonos de la imagen del mundo establecida, del imperio del man, de la repetición, de la espera e incluso del aburrimiento.

Según Fichte debemos buscar aquí al sabio, al auténtico intelectual, su destino, y con él el de la filosofía: el saber no puede contenerse, satisfacerse entre unas fronteras demarcadas de antemano, sino que debe ser comprendido desde la libertad; liberador. Si hubiera un conocimiento que no nos liberara de nada, no sería en sentido estricto conocimiento, porque conocer es en sí mismo liberarse realizando -dicho a la Spinozatodo su pouissance $e^{45}$. Dicha libertad que somos, y que sólo puede ser intuida, es posible por la constatación constante de un no-yo que hace de obstáculo, que hace que nazca la conciencia como conciencia de noreconocimiento; de modo que el Ichbeit sabe de sí mismo como negación activa. Mucho después, Heidegger, en 1927, utilizará la expresión proyecto para designar esta especial concepción existencial de la comprensión ${ }^{46}$. Para entonces la Ichbeit de Fichte es ya una Inheit ${ }^{47}$ resaltándose que ese yo está esencialmente en un mundo que al conocer permite que nos proyectemos. El No-yo de algún modo se ha transformado, podríamos decir, en el ahí del yo, o el en del yo: que forma parte de él y que designa una forma de estar (y de ser) del yo, un existenciario. Quizás sea aquí donde desemboca la línea Kant-Fichte, que siempre fue de algún modo la línea fenomenológica, la línea que defiende que todo cogitatum lo es de una conciencia pensante. ${ }^{48}$ No hay pues una ruptura con Kant, sino una continuación en la que se produce una transformación acorde con los tiempos, como no podía ser de otra manera, en la que Kant es transformado por Fichte y este por otros, hasta llegar a Husserl y Heidegger.

En esta línea filosófica lo que toma forma es una peculiar filosofía de la libertad ${ }^{49}$ que asume que la ciencia no puede garantizar la libertad si sólo quiere saber de cosas, porque el pensamiento libre desborda el juicio

\footnotetext{
45 "Posse existere potentia est - la puissance, c'est de pouvoir exister", E1P11.

46 Sein und Zeit, GA 2, 145.

${ }^{47}$ Ibid., p. 53.

${ }^{48}$ Cfr., MONTERO, F., Retorno a la fenomenología, Anthropos, Barcelona, 1987, p. 470.

49 "Si una filosofía, en efecto, puede concebirse "filosofía de la libertad" y filosofía de la acción "es ésta, especialmente la fichteana”, TRÍAS, E., Tratado de la pasión, Debolsillo, Barcelona, 2013, p. 59.
} 
determinante y se reconoce reflexivo, dialéctico, "desgarrado entre el proceso de establecerse y el fijismo derivado de ese proceso, desgarrado entre su carácter fundacional y originario de actividad o productividad pura de pensamiento que se piensa y el resultado o derivado de esa acción que es el campo objetivo que abre". ${ }^{0}$

El contrapunto hoy -como ocurriera en la época de Fichte- es nuevamente el positivismo; la idea de que la ciencia -o los hombres de ciencia- nos traerán las soluciones para los problemas reales. Tenemos que abordar una vez más la decisión de desarrollar una filosofía de la libertad frente a una filosofía positivista en la que esta libertad se vea como amenaza para un conocimiento que, en ausencia de aquella, se vuelve metódico (para el escándalo de Feyerabend) e incluso inhumano, ${ }^{51}$ en la medida en que destierra todo aquello sin la cual la comprensión humana se vuelve precisamente inhumana: la pasión, la oposición, el querer, la tradición, etc. Hoy tenemos una vez más que decidirnos entre positivismo e idealismo, pero no para repetirlos (lo que sería anacrónico), sino para continuarlos, transformarlos y darle una nueva forma acorde con nuestros tiempos. Eso mismo fue lo que hizo en su momento Fichte con Kant: continuarlo transformándolo. Una continuación-transformación que se puede resumir diciendo que con Fichte se transforma el "Wie ist Metaphysike als Wissenschaft möglich?" en wie ist die Wissenschaft beriehunsweise das Wissen selbst möglich?, con todo lo que esto significa de abandonos, rupturas, transformaciones e incluso rechazos.

Las grandes continuaciones simpre han dado lugar a algo nuevo cuando han sido tomadas en serio, es decir, cuando no han sido meras repeticiones. Ni hoy tiene sentido repetir a Fichte, ni lo tenía para Fichte repetir a Kant, pero continuar su camino, andarlo, recorrerlo con ellos -y contra ellos-, de la mano unas veces y otras a bofetadas, elogiando y criticando... es la forma más sublime de continuar una filosofía, de proseguir una tarea, de dignificar y respetar a los maestros y sus proyectos. Y ello pese a lo que piensen Kant de Fichte, Husserl de Heidegger o Platón de Aristóteles.

\footnotetext{
${ }^{50}$ Ibid., p. 61.

${ }^{51}$ BUTTERFIELD, H., The Whig Interpretation of History, New York, Norton, 1965, p 66 y p. 21.
} 


\section{Bibliografía.}

BUTTERFIELD, H. (1965), The Whig Interpretation of History, New York: Norton.

CUBO, O., (2012), Kant. Sentido común y subjetividad, Plaza y Valdés: Madrid.

DIÉGUEZ, A. (2005), Filosofía de la ciencia, Madrid: Biblioteca Nueva

DUQUE, F. (1998), Historia de la filosofía moderna. La era crítica, Akal: Madrid.

FEYERABEND, P. (2003), ¿Por qué no Platón?, Madrid: Tecnos.

FICHTE, J-G (1845ss), Sämmtliche Werke, edición de I. H. Fichte: Berlin.

- (1962ss), J. G. Fichte-Gesamtausgabe der Bayerischen Akademie der Wissenschaften: Stuttgart.

GARCÍA, J. A., (2014), "El empirismo y la filosofía hoy", en ROJASGARCÍA (eds), El idealismo alemán y sus consecuencias actuales, Contrastes , Suplemento 19, 159-177.

HEIDEGGER, M. (1973), Kant y el problema de la metafísica, trad. C. Ibicher, FCE, México.

- (1977) Sein und Zeit, GA 2, Klostermman: Frankfurt.

- (1986) Nietəsche. Der europäische Nibilismus, GA 48: Frankfurt: Klostermann.

JACOBS, W. G. (2014), Johann Gottlieb Fichte. Eine Einführung, Suhrkamp: Berlin.

KANNT, I. (1783), Prolegomena, Akademie Ausgabe, IV.

- (1990ss), Gesammelten Schriften, Akademie-Ausgabe: Berlin.

LEYTE, A (2014), "Infinito romántico", en ROJAS-GARCÍA (eds), El idealismo alemán y sus consecuencias actuales, Contrastes, Suplemento 19, 205222.

MONTERO, F. (1987), Retorno a la fenomenologia, Anthropos: Barcelona. RAMOS, M. (2006), "La libertad en el principio de la Doctrina de la Ciencia de Fichte", Quaderns de filosofia i ciència, 36, 51-59.

ROJAS, A (2014), Das Potenzlose: Hildesheim: Olms.

- (2014), "El bien y la intelección en Platón", Thémata 5/ juliodiciembre, 37-68.

- (2014), La deuda inconfesada de Heidegger, Universidad de Málaga: Málaga.

SPINOZA, B. (2012), Éthique démontrée suivant l'ordre géométrique, edición de Henrique Díaz disponible on-line : http://spinozaetnous.org/wiki/E (enlace copiado a 02.11.2015)

Claridades. Revista de filosofía 8 (2016) 
STROUD, B. (1977), Hume, Routledge \& Kegan Paul: London.

TRÍAS, E (2013), Tratado de la pasión, Debolsillo: Barcelona, 2013.

ALEJANDRO RojAS es profesor de filosofía en la Universidad de Málaga, presidente de FICUM y miembro del grupo de investigación andaluz sobre el idealismo actual y sus consecuencias actuales.

Lineas de investigación:

Heidegger, Schelling, idealismo alemán, Platón, teorías de la verdad.

Publicaciones recientes:

- „Von der Unheimlichkeit und der Auffassung der Welt in der Spätphilosophie Heideggers“, Fenomenologia. Pismo Polskiego Towarzystma Fenomenologicznego 13, (2015) 143-154.

- Indicación de la situación hermanéutica que envuelve a la filosofía platónica“, en Anales del seminario de bistoria de la filosofía 32, II (2015), 315.343.

- „Die Idee des Potenzlosen in der Spätphilosophie Schellings und in der Spätphilosophie Heideggers“, Philosophisches Jabrbuch 121, I (2014), 92-110.

Dirección electrónica: rojas_a@uma.es

Claridades. Revista de filosofía 8 (2016) 